
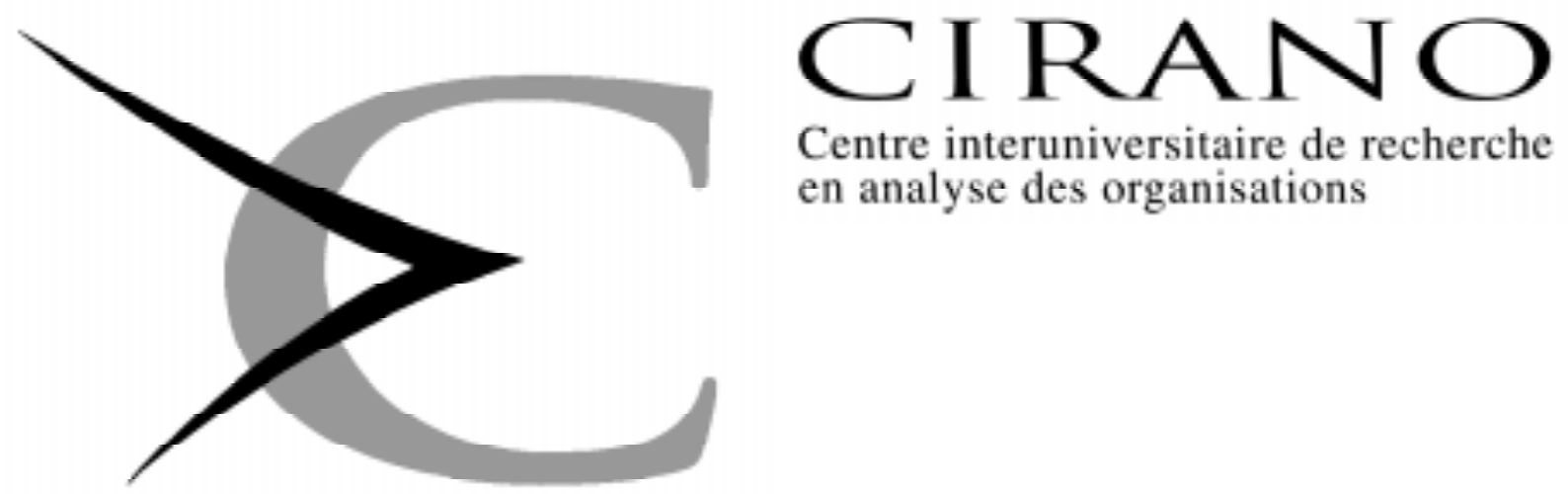

Série Scientifique

Scientific Series

$96 s-21$

Environmental Auditing

in Management Systems and Public Policy

Bernard Sinclair-Desgagné, H. Landis Gabel 


\section{CIRANO}

Le CIRANO est une corporation privée à but non lucratif constituée en vertu de la Loi des compagnies du Québec. Le financement de son infrastructure et de ses activités de recherche provient des cotisations de ses organisations-membres, d'une subvention d'infrastructure du ministère de l'Industrie, du Commerce, de la Science et de la Technologie, de même que des subventions et mandats obtenus par ses équipes de recherche. La Série Scientifique est la réalisation d'une des missions que s'est données le CIRANO, soit de développer l'analyse scientifique des organisations et des comportements stratégiques.

CIRANO is a private non-profit organization incorporated under the Québec Companies Act. Its infrastructure and research activities are funded through fees paid by member organizations, an infrastructure grant from the Ministère de l'Industrie, du Commerce, de la Science et de la Technologie, and grants and research mandates obtained by its research teams. The Scientific Series fulfils one of the missions of CIRANO: to develop the scientific analysis of organizations and strategic behaviour.

\section{Les organisations-partenaires / The Partner Organizations}

-École des Hautes Études Commerciales.

-École Polytechnique.

-McGill University.

-Université de Montréal.

- Université du Québec à Montréal.

-Université Laval.

-MEQ.

-MTCST.

-Avenor.

-Banque Nationale du Canada

-Bell Québec.

-Fédération des caisses populaires de Montréal et de l'Ouest-du-Québec.

-Hydro-Québec.

-La Caisse de dépôt et de placement du Québec.

-Raymond, Chabot, Martin, Paré

- Société d'électrolyse et de chimie Alcan Ltée.

-Téléglobe Canada.

- Ville de Montréal.

Ce document est publié dans l'intention de rendre accessibles les résultats préliminaires de la recherche effectuée au CIRANO, afin de susciter des échanges et des suggestions. Les idées et les opinions émises sont sous l'unique responsabilité des auteurs, et ne représentent pas nécessairement les positions du CIRANO ou de ses partenaires.

This paper presents preliminary research carried out at CIRANO and aims to encourage discussion and comment. The observations and viewpoints expressed are the sole responsibility of the authors. They do not necessarily represent positions of CIRANO or its partners.

ISSN 1198-8177 


\title{
Environmental Auditing in Management Systems and Public Policy"
}

\author{
Bernard Sinclair-Desgagnés ${ }^{\dagger}$, H. Landis Gabel
}

Résumé / Abstract

\begin{abstract}
De nouvelles normes pour les audits environnementaux sont actuellement en train d'être élaborées et implantées par les gouvernements et les entreprises. Ces normes mettent principalement l'accent sur les systèmes de gestion et les incitations qui encouragent un meilleur usage des ressources environnementales. Cet article étudie un tel système, où la rémunération pourrait dépendre en partie des conclusions d'un audit environnemental. On trouve que le salaire versé après la tenue d'un audit devrait varier davantage que celui versé lorsqu'il n'y a pas eu d'audit. On montre aussi que la décision d'effectuer un audit environnemental et le niveau du salaire espéré dans ce cas dépendent essentiellement de la relation entre la prudence (ou la précaution) et l'aversion pour le risque du manager. On montre finalement que l'insertion d'audits environnementaux au sein des systèmes managériaux usuels poussera certainement un manager à se préoccuper davantage de l'environnement, mais la redistribution de l'effort de ce dernier pourrait bien ne pas survenir au détriment de ses activités principales au sein de l'entreprise. On discute enfin brièvement du rôle et de l'intérêt du décideur public dans l'élaboration et la promotion de nouvelles normes pour les audits environnementaux.
\end{abstract}

New international standards for environmental auditing are now being actively promoted by public authorities and adopted by private firms. One important feature of these standards is their emphasis on managerial systems and incentives that support a wiser use of environmental resources. This paper studies such a system, in which incentive compensation may be based in part on the results of an environmental audit. It is found that optimal wages after an environmental audit is performed should have a greater range than wages paid when no audit has occured. It is also shown that the decision to conduct an environmental audit and the size of the expected wage in this

"Correspondence Address: Bernard Sinclair-Desgagnés, CIRANO, 2020, University Street, 25th floor, Montréal, Qc, Canada H3A 2A5 Tel: (514) 985-4025 Fax: (514) 985-4039 e-mail: desgagnb@cirano.umontreal.ca

We acknowledge valuable conversations with and comments from Rabah Amir, John Braden, Olivier Cadot, Christian Gollier, John Hartwick, Jean-Jacques Laffont, Fatma Lajeri, Lars-Hendrik Röller, and David Soskice. Part of this paper was written while Sinclair-Desgagnés was visiting the Wissenschaft-zentrum-Berlin, in May-June 1996. This research was funded by CIRANO, the Center for the Management of Environmental Resources of INSEAD, and a strategic research grant from the Social Sciences and Humanities Research Council of Canada.

${ }^{\dagger}$ École Polytechnique de Montréal and CIRANO

${ }^{\ddagger}$ INSEAD 
case depend crucially on whether the agent's prudence for precautionary motives) dominates or not his aversion to risk. It is finally found that the insertion of environmental audits within current management systems would certainly induce a manager to care more about the environment; moreover, although this may come at the expense of less concern for other activities, we find plausible circumstances in which properly designed environmental audits overcome such a tradeoff and increase the manager's attention to both environmental and traditional tasks. The public policy maker's role and interest in promoting environmental auditing standards are also discussed briefly.

Mots Clés : $\quad$ Analyse principal-agent multi-tâches, Audits environnementaux, Aversion pour le risque, Prudence

Keywords : $\quad$ Multi-Task Principal-Agent Analysis, Environmental Auditing, Risk Aversion, Prudence

JEL : D82, L15, M49 


\title{
1. INTRODUCTION
}

\author{
"What you don't know will hurt you." \\ [F. Friedman, Vice-President, Occidental Petroleum Corporation, \\ in a speech to the Chemical Manufacturers' Association, 1983] ${ }^{1}$
}

Since its first (mandatory) introduction in the US chemical and steel industries in the late 1970s, environmental auditing has become a major tool for the management of environmental resources [5, 11, 12, 18, 24]. Nowadays, environmental audits are being routinely conducted within companies to define the extent of their liabilities towards the environment, to check compliance with environmental legislation, to test newly acquired land or buildings, and to assess environmental risks, employees' safety, energy consumption, waste streams or pollutant emissions $[6,15,34]$. Yet, despite its widespread use, environmental auditing remains an evolving discipline. It seems quite likely that its practice will change significantly in the near future. This assertion is based on the recent development, and active promotion by public authorities, of international standards for the practice of environmental audits and certification of environmental auditors $[4,7,8,9]$.

Typical of these new standards is their emphasis on so-called "environmental management systems", i.e. the way business and industry are structured to address environmental, health or safety compliance and risk. The influential International Organization for Standardization (ISO), for instance, devotes a section of its forthcoming ISO 14000 standards - actually the first section of its Guidelines for Environmental Auditing - to audit procedures directed at such systems [32]. This raises a number of issues. First, there is the matter of fit with mainstream management systems such as financial appraisal and bonus calculation. This is especially important if the new (tougher) standards for environmental auditing are to be adopted voluntarily by industry. A related and key question is the impact on business decision-making of carrying out environmental audits according to the new norms. These issues are the topic of this paper.

At this point, given the relatively short history of environmental auditing and the consequent scarcity of data, we must rely on formal analogies and theory to address them. An obvious starting point is the extensive theoretical literature on corporate audits, which is based on the principal-agent model. This literature

\footnotetext{
${ }^{1}$ Quoted by Cahill and Kane [6], p. xii-1.
} 
distinguishes two kinds of audits: those aiming to verify a declared outcome, for example an announced return [26,33], and those that provide information on a key input, for example the agent's effort $[1,10]$. The actual philosophy of environmental auditing seems to favor the latter kind [see 32]. Our model will therefore be similar to the one used by Baiman and Demski [1]. There is one major difference, however. The matter here is not the total amount of effort that the agent delivers, but rather the allocation of this effort between environmental and nonenvironmental tasks. So building on recent studies $[2,3,17]$ and our earlier work [13], we use a multi-task principal-agent model. In such a model, the agent must allocate effort between, say, a financial task and an environmental task. ${ }^{2}$ This allocation cannot be observed by the principal who can only infer the agent's effort from some imperfect measure of performance on each task. Previous models of this sort assumed costless and constant monitoring of the variables of interest - the agent's effort on each task. In reality, every monitoring system is costly, and the principal may decide against constant monitoring. In this paper, we suppose therefore that financial performance is always monitored, but we endogenize the principal's decision to audit the agent's degree of environmental diligence.

The model provides new insights for the management integration of environmental auditing. One first result is that optimal wages after an environmental audit is performed should have a larger range than wages paid when no audit has occurred. A second finding is that in this context the agent's allocation of effort is essentially determined by whether his prudence (in the sense of Kimball [22]) is stronger or weaker than his aversion to risk; hence, the relationship between these two features of the agent's utility will guide the optimal design of environmental audits. When prudence dominates, for instance, it is better to run an environmental audit if current profits are high and to offer the agent a larger expected wage each time an audit takes place. Concerning the impact of environmental audits on business decision-making, the model also indicates that the insertion of environmental audits within current management systems would certainly induce the agent to care more about the environment. Whilst this may come at the expense of less concern for non-environmental activities, we find

\footnotetext{
2 The name "multi-task principal-agent problem" might leave the impression that the agent is actually performing several different assignments simultaneously, which he is not. An example of what we have in mind here is, for instance, a project evaluator who might be more or less careful in assessing the environmental impact of a proposal along with its financial prospects. John Hartwick suggested that we rather call the problem a "multi-impact principal-agent problem". Indeed, this describes more clearly the generic situation that we model. We will keep using the previous name, however, only to remain consistent with the literature.
} 
plausible circumstances in which optimal environmental audits overcome this tradeoff and induce the agent to increase his attention to both environmental and non-environmental tasks. The intuition for this result is straightforward when the agent's prudence dominates his aversion to risk. In this case, the agent's wishes to be audited and of course that the audit result be a good one. Hence, the agent would tend to work harder on financial tasks, in order to make high profits more likely, but also on environmental tasks, in order to increase the probability that the conclusion of an environmental audit be favorable.

The paper is organized as follows. The next section summarizes the relevant institutional background that surrounds environmental auditing and the related issues we address. Section 3 presents the multi-task principal-agent model. Section 4 states and discusses the results. Section 5 contains conclusions and remarks for environmental public policy.

\section{BACKGROUND}

For many years, auditing has been a key tool of the financial accounting profession. ${ }^{3}$ Environmental auditing, however, began to appear only in the late seventies in large US firms such as US Steel (in 1977), Allied Chemical (in 1979), General Motors and ARCO, as a response to rising environmental worries. ${ }^{4}$ In the 1980 s, the practice of environmental auditing spread further, particularly across the chemical industry, under the public and regulatory impact of the Bhopal disaster and new insurance contracts linking insurance fees to environmental risks and pollution. In 1988, the US and Canadian Chemical Industry Associations jointly adopted the Responsible Care Programme, which was the first significant multi-firm initiative that specified environmental audits.

Those audits sought primarily to check compliance with environmental regulations and their results were intended for a company's eyes only. There was no precise common view of what an environmental audit was or how it should be done. Words such as eco-audit, environmental audit, environmental impact

\footnotetext{
3 Auditing seems to be an old practice indeed: it appears to date at least as far back as the Roman Empire. In those days announcements from the authorities were communicated through official messengers. To ensure that the announcements were made correctly, "auditors", who knew the announcements just as well as the messengers did, accompanied them. The latin root of the word auditing means listening (reported in Stans [32]).

${ }^{4}$ For case studies of some of these companies and a description of audit methodology at that time, see Harrison [15].
} 
assessment (EIA), waste and emissions audit, and cleaner production assessment were given different meaning or were used interchangeably in various parts of the world. Moreover, although the Responsible Care Programme noted the value of audits as a tool for management evaluation and supervision, environmental auditing was generally not integrated with any management control system [see 34].

By the early 1990s, company environmental audits were becoming quite common, and the International Chamber of Commerce (ICC) had started to promote them. The latter's following definition made precise the multiple purposes of environmental auditing and pressed for its embedding into broader management systems. According to the ICC [18]:

[An environmental audit is] a management tool comprising systematic, documented, periodic and objective evaluation of how well environmental organization, management and equipment are performing, with the aim of helping to safeguard the environment by facilitating management control of environmental practices and assessing compliance with company policies, which would include meeting regulatory requirements. [18, p. 6; emphasis added]

At that time, a drive for quality was transforming industry. International quality management norms, such as the ISO 9000 which sets up quality audits, were gaining worldwide acceptance. In this context, the British Standard Institute published in 1992 the first standard - the BS 7750 - for a management system incorporating environmental auditing. ISO itself made a proposal for an international standard of corporate environmental management at the Rio de Janeiro 1992 Earth Summit. This lead to an update of current ISO norms - the ISO 14000 which will include requirements for environmental management and auditing.

On April 10, 1995, the European Commission (EC) announced the implementation of its so-called Eco-Management and Audit Scheme (EMAS). It is now part of the Commission's environmental policy apparatus, and some firms have already won registration under it. (In the United Kingdom, for instance, five firms were registered in August 1995.) At the time of this writing, however, there is still some debate about details of EMAS implementation. The principal issues in dispute are the relationship between EMAS and the other environmental management standards mentioned above, and the criteria for validating compliance with standards. The EC did not want to use any existing national standards, which rules the BS 7750 out of consideration for automatically satisfying EMAS. The Commission has not recognized the ISO standards either, because it estimates that 
international negotiations have rendered those standards "too weak". 5

There may be several differences between the various auditing standards, but there also are important common characteristics. First, these new standards are generic: although they are mainly directed at industrial firms (as opposed, for instance, to banks or public services), they are not tailored to any specific industry. Second, and consequently, these norms are not concerned with measurements of the environmental impact of a firm's activities. Rather, they are flexible procedural guidelines for how to conduct an environmental audit and requirements for selecting auditors. Third, these standards specify the scope of an environmental audit. The audit report should include, for instance, an analysis of corporate policy statements, management control systems, process controls, inspection and recordkeeping procedures, agreements with waste contractors, training activities, and emissions records.

Finally, a fourth common feature of the new auditing rules is that they make environmental auditing an integral part of broader, albeit still nascent, environmental management systems. In a regulation statement concerning company participation in EMAS, the European Commission emphasizes such systems, defining them as:

(...) that part of the overall management system which includes the organizational structure, responsibilities, practices, procedures, processes and resources for determining and implementing the environmental policy. (quoted in [34], p. 7)

A recent statement by the ISO articulates this definition further.

Key principles for managers implementing an environmental management system include, but are not limited to, the following:

- develop management and employee commitment to the protection of the environment, with clear assignment of accountability and responsibility; (...)

- establish a disciplined management process for achieving targeted performance levels; (...)

- assess environmental performance against appropriate policies, objectives and targets and seek continual improvement where

\footnotetext{
5 Analyzing the standards-building process is of course beyond the scope of this paper. For the interested reader, let us simply mention that American firms are especially fearful of being found legally liable for infractions revealed by the audits - a risk that their European counterparts do not face. In fact, not only are US firms liable for violations they uncover, they are also legally obliged to report their findings to the prosecuting authorities. Of course, this provides them with strong incentives not to look for problems.
} 
appropriate (...). (quoted in [34], p. 8; emphasis added]

As many researchers, consultants and business persons have remarked, however, fulfilling such principles presupposes that they be feasible within a mainstream management system and its current rewards and financial incentives. ${ }^{6}$ Actually, they may not: surveys of management practice $[24,31]$ suggest that companies do not explicitly link environmental audit results to the evaluation and compensation of employees. One goal of this paper is to examine whether this is nevertheless possible (and desirable). The analysis that follows concedes that protecting the environment is not the main objective of the firm, but the principal may consent to do so because environmental negligence can have significant consequences on profit. The agent is therefore expected to first take care of traditional business functions but to devote a "reasonable" fraction of his time to environmental protection. The agent's compensation is linked to his performance in regular business tasks, which is routinely monitored, and to his environmental performance whenever it is audited. Ultimately, the presence of verifiable environmental audits that influence compensation should change the agent's effort allocation and the principal's profit.

\section{THE MODEL}

The introduction of environmental audits in a firm can be viewed as an amendment to current management information systems. Since Holmström's [16] seminal work (see also Kim [21]), formal economic studies of such systems have been done using principal-agent modelling. Although these studies were prompted by problems specific to the fields of accounting and corporate finance, direct analogies can now be made between financial and environmental audits. Indeed, the widespread adoption of publicly-endorsed international norms of environmental auditing should make it possible to draw explicit contracts that make compensation contingent on environmental performance. This supports the modelling approach that follows.

Consider a one-period principal-agent relationship in which the agent must split his effort between "regular" (profit-generating) activities and environmental protection. Let the amount of effort spent on regular activities and environmental

\footnotetext{
${ }^{6}$ See, for instance, ICC [18]: "To be effective, [audit] reviews need to be conducted within a structured management system, integrated with overall management activity."
} 
protection be denoted by $x$ and $y$ respectively. The agent can vary both his total effort and the allocation of that effort between the two tasks. The principal can observe neither the agent's total effort nor its allocation; she can, however, receive estimates $\pi$ and $\epsilon$ of the revenues generated or environmental costs reduced by the agent's effort level and allocation. Those estimates are drawn from a finite subset of real numbers according to the information technology $g(\pi, \epsilon / x, y){ }^{7}$ We shall make the following standard assumptions about $g$.

ASSUMPTION 1: $g(\cdot / x, y)$ is strictly positive on its domain, for all $x, y$. At each vector $(\pi, \epsilon)$, it is twice continuously differentiable in $(x, y)$.

Effort on regular duties is easily and routinely monitored through the firm's standard financial reporting system. By contrast, effort to protect the environment is costly to assess, so environmental audits may be infrequent. On the basis of the information available $(\pi)$ from financial monitoring, the principal may audit the agent with probability $m(\pi)$. If an environmental audit is done, a fixed $\operatorname{cost} K$ is incurred and the estimate $\epsilon$, which can be positive or negative, is received. The principal then corrects her estimate of expected total profit (before wage and audit costs) to $\pi+\epsilon$. Note that although efforts on the two activities are assessed differently, we assume that the impact of each can be expressed in money terms. ${ }^{8}$

We shall now suppose that the influence of effort levels $x$ and $y$ on the signals $\pi$ and $\epsilon$ can be perfectly separated: that is, $y$ has no (direct) influence on $\pi$ and the same holds for $x$ with respect to $\epsilon$. Hence, the information technology $g$ will be conceived as the product of two one-dimensional probability distributions.

ASSUMPTION 2: $\quad g(\pi, \epsilon / x, y)=f(\pi / x) h(\epsilon / y)$.

This restriction of course simplifies the analysis. More importantly, it captures, first, the fact emphasized above that environmental audits are a priori extraneous to current management information systems, so they may not convey much additional information on the way standard managerial tasks are handled, and

\footnotetext{
${ }^{7}$ Assuming that the set of signals is finite instead of continuous does not bear any consequences on results. It just simplifies the exposition.

${ }^{8}$ This is clear enough in the case of fines for environmental damage. But financial values can be assigned as well to less explicit costs or benefits of environmental performance, such as its impact on company reputation to customers, employees, shareholders, and community residents.
} 
second, the idea that there may actually be no means but environmental audits to assess the agent's degree of environmental care.

The principal is assumed to be risk neutral. The agent's behavior fits the following assumptions.

ASSUMPTION 3: The agent has a utility $U:(\underline{z}, \infty) \rightarrow \mathbb{R}_{+}$for money that is strictly increasing, continuously differentiable, and strictly concave (i.e. exhibits strict risk aversion). An effort vector $(x, y)$ costs the agent $C(x+y)$, where the function $C: \mathbb{R}_{+} \rightarrow \mathbb{R}_{+}$is increasing, convex and twice continuously differentiable. $C(0)=0$, $\mathrm{C}^{\prime}(0)=0$, and $\mathrm{C}^{\prime}(\infty)=\infty$.

The first part of assumption 3 is a standard one. The second part means that there are decreasing returns to total effort, but that the agent is indifferent ex ante between spending effort on regular activities or on environmental protection. ${ }^{9}$

The principal can now offer the agent a contract which includes the possibility of an unannounced environmental audit and which makes the paid wage in this case contingent on audit results. How frequently, or whether, audits are actually done under this contract is a discretionary decision of the principal. There are economic limitations to such a contract, however. First, it must provide the agent with a utility at least equal to his reservation utility $U^{*}$, so that the agent would voluntarily accept the contract; this is the so-called individual rationality or participation constraint. Second, it must take into account the fact that the agent will set his effort level and allocation in order to maximize his own utility; this is the incentive compatibility constraint. Let $s(\pi)$ denote the agent's wage when only the estimate $\pi$ is gathered, and $w(\pi, \epsilon)$ be the wage if there is an environmental audit. The optimal contract will then be a solution to:

$$
\begin{gathered}
\max _{m, s, w, x, y} \sum_{\pi, \epsilon}[m(\pi)(\pi+\epsilon-w(\pi, \epsilon)-K)+(1-m(\pi))(\pi+\epsilon-s(\pi))] g(\pi, \epsilon \mid x, y) \\
\text { subject to: } \\
(x, y) \epsilon \underset{x, y}{\operatorname{argmax}} \sum_{\pi, \epsilon}[m(\pi) U(w(\pi, \epsilon))+(1-m(\pi)) U(s(\pi))] g(\pi, \epsilon \mid x, y)-C(x+y) \\
\sum_{\pi, \epsilon}[m(\pi) U(w(\pi, \epsilon))+(1-m(\pi)) U(s(\pi))] g(\pi, \epsilon \mid x, y)-C(x+y) \geq U^{*}
\end{gathered}
$$

\footnotetext{
9 The principal's risk neutrality and the agent's indifference between tasks are not crucial assumptions, but they again ease the analysis significantly.
} 
This is a typical principal-agent problem with multiple tasks and signals. An additional decision variable for the principal here is $m(\pi)$, the probability of auditing the agent following observation of the profit estimate $\pi$.

\section{The first-order approach}

The incentive compatibility constraint of problem (1) is rather complex: it hides a continuum of inequality constraints. To make the problem tractable, one may replace it by (an approximation of) the first-order necessary conditions for having a stationary point of the agent's expected utility. This leads to the modified problem:

$$
\begin{gathered}
\max _{m, s, w, x, y} \sum_{\pi, \epsilon}[m(\pi)(\pi+\epsilon-w(\pi, \epsilon)-K)+(1-m(\pi))(\pi+\epsilon-s(\pi))] g(\pi, \epsilon \mid x, y) \\
\quad \text { subject to: } \\
\sum_{\pi, \epsilon}[m(\pi) U(w(\pi, \epsilon))+(1-m(\pi)) U(s(\pi))] g_{x}(\pi, \epsilon \mid x, y)-C^{\prime}(x+y) \geq 0 \\
\sum_{\pi, \epsilon}[m(\pi) U(w(\pi, \epsilon))+(1-m(\pi)) U(s(\pi))] g_{y}(\pi, \epsilon \mid x, y)-C^{\prime}(x+y) \geq 0 \\
\sum_{\pi, \epsilon}[m(\pi) U(w(\pi, \epsilon))+(1-m(\pi)) U(s(\pi))] g(\pi, \epsilon \mid x, y)-C(x+y) \geq U^{*}
\end{gathered}
$$

The approach that consists in solving this problem instead of problem (1) is called the first-order approach. What matters of course is that all solutions to problem (2) be also solutions to problem (1). It can be shown that this is the case under the next assumptions, provided the solution $m(\pi)$ increases with $\pi$ (see [30]).

ASSUMPTION 4: [Monotone likelihood ratio property] The ratios $f_{\mathrm{x}}(\pi / x) / f(\pi / x)$ and

$h_{y}(\epsilon / y) / h(\epsilon / y)$ are nondecreasing in respectively $\pi$ and $\epsilon$, for every vector $(x, y){ }^{10}$

ASSUMPTION 5: [Monotonicity and convexity of the distribution function] The upper

cumulative probability distributions $\sum_{(\pi, \epsilon)>(\mathbb{\pi}, \epsilon)} \mathrm{g}(\pi, \epsilon \mid \mathrm{x}, \mathrm{y})$ are increasing and

\footnotetext{
${ }^{10}$ The subscripts ${ }_{\mathrm{x}}$ and ${ }_{\mathrm{y}}$ denote partial derivatives with respect to $x$ and $y$ respectively.
} 
concave in $(x, y)$.

ASSUMPTION 6: The first two constraints of problem (2) are both either strictly binding or

nonbinding (i.e. their respective associated multipliers have the same sign).

When $m(\cdot)$ is not an increasing function, however, the first-order approach may fail. We will simply assume that this is not the case here.

This completes the description of the model. We shall now turn to the derivation and discussion of results.

\section{RESULTS}

Section 2 raised several questions concerning the integration of environmental auditing within mainstream management systems. We will now try to answer those questions using the above principal-agent model. The first subsection explores the possible use of environmental audits as an input for incentive compensation. The second subsection studies the optimal occurrence of environmental audits. The third and last subsection focuses on the resulting effort allocation chosen by the agent.

\section{Environmental audits and incentive compensation}

A key role of management systems is to align employees' private objectives with those of the firm. Increased environmental awareness on the part of shareholders and corporate board members will not change the firm's environmental record in a significant and durable way unless it is translated into concrete amendments of the existing managerial system. In many firms, an important component of such a system is incentive pay which varies wages according to measured performance. This subsection formally investigates how incentive pay should be modified to incorporate the assessments of environmental performance that come from environmental audits.

In the present framework, the incentive wage schedule that is put in place by the principal would satisfy the first-order necessary conditions for an optimum of problem (2). Let $\gamma, \lambda, \delta$ be the Lagrange multipliers attached to the first, second and third constraints of (2) respectively. (Note that, these contraints being inequalities, their associated multipliers can and will always be made nonnegative in the expressions below.) The first two multipliers, $\gamma$ and $\lambda$, are the shadow prices 
of the incentive compatibility constraints on efforts $x$ and $y$ respectively. They measure the increase in the principal's profit resulting from a marginal deviation by the agent from his utility-maximizing effort on regular and environmental activities respectively. The third multiplier, $\delta$, is the shadow price of the participation constraint, which captures the increase in the principal's profit from a marginal decrease in the agent's reservation utility, $U^{*}$. The necessary conditions for $s$ - the incentive wage without an environmental audit - are now:

$$
\forall \pi:(1-m) \sum_{\epsilon}\left[-f h+\gamma U^{\prime}(s) f_{x} h+\lambda U^{\prime}(s) f h_{y}+\delta U^{\prime}(s) f h\right]=0 .
$$

Those conditions for $w$ - the incentive wage after an environmental audit - are:

$$
\forall(\pi, \epsilon): \quad m\left[-f h+\gamma U^{\prime}(w) f_{x} h+\lambda U^{\prime}(w) f h_{y}+\delta U^{\prime}(w) f h\right]=0 .
$$

Forgetting $m(\pi)$ for the moment, (3) and (4) can be rewritten respectively as

$$
\begin{gathered}
\forall \pi: \frac{1}{U^{\prime}(s(\pi))}=\delta+\gamma \frac{f_{x}(\pi \mid x)}{f(\pi \mid x)}, \text { and } \\
\forall(\pi, \epsilon): \quad \frac{1}{U^{\prime}(w(\pi, \epsilon))}=\delta+\gamma \frac{f_{x}(\pi \mid x)}{f(\pi \mid x)}+\lambda \frac{h_{y}(\epsilon \mid y)}{h(\epsilon \mid y)} .
\end{gathered}
$$

Equations (5) and (6) must clearly be satisfied when $0<m(\pi)<1$. Note, however, that they can be made to hold as well if $m(\pi)=1$ or 0 .

A key relationship between $s(\pi)$ and $w(\pi, \epsilon)$ can be derived from the above equations. Subtracting (6) from (5), one gets

$$
\forall(\pi, \epsilon): \quad \frac{1}{U^{\prime}(s(\pi))}-\frac{1}{U^{\prime}(w(\pi, \epsilon))}=-\lambda \frac{h_{y}(\epsilon \mid y)}{h(\epsilon \mid y)} .
$$

We can now state some general characteristics of the optimal wage schedule.

PROPOSITION 1: Under the above assumptions, $s(\pi)$ and $w(\pi, \epsilon)$ have the following properties:

(i) $s$ and $w$ are nondecreasing in their respective arguments. 
(ii) $s(\pi) \geq w(\pi, \epsilon)$ when $\epsilon$ is small and $s(\pi) \leq w(\pi, \epsilon)$ when $\epsilon$ is large.

(iii) $\forall \pi: \sum_{\epsilon} w(\pi, \epsilon) h(\epsilon / y) \geq(\leq) s(\pi)$ if $-2\left(U^{\prime \prime} / U^{\prime}\right) \leq(z)-U^{\prime \prime \prime} / U^{\prime \prime}$.

PROOF: Statement (i) comes directly from the assumptions, in particular assumption 4 , and equations (5) and (6).

To show statement (ii), consider (7) and note that, since $\Sigma_{\epsilon} h_{\mathrm{y}}(\epsilon / y)=0$ and $h_{\mathrm{y}} / h$ is nondecreasing in $\epsilon$, it must be the case that $h_{\mathrm{y}}(\epsilon / y) \leq 0$ when $\epsilon$ is small and $h_{y}(\epsilon / y) \geq 0$ when $\epsilon$ is large. The result now comes from the fact that $1 / U^{\prime}(\cdot)$ is an increasing function.

To prove (iii), first take the expectation with respect to $\epsilon$ on both sides of equation (7). This gives

$$
\forall \pi: \quad \frac{1}{U^{\prime}(s(\pi))}-\sum_{\epsilon} h(\epsilon \mid y) \frac{1}{U^{\prime}(w(\pi, \epsilon))}=0 .
$$

If $-2\left(U^{\prime \prime} / U^{\prime}\right) \leq-U^{\prime \prime \prime} / U^{\prime \prime}$, then $1 / U^{\prime}$ is a concave function. By Jensen's inequality we have that

$$
\forall \pi: \quad \frac{1}{U^{\prime}(s(\pi))}-\frac{1}{U^{\prime}\left(\sum_{\epsilon} w(\pi, \epsilon) h(\epsilon \mid y)\right)} \leq 0 .
$$

Hence $\forall \pi: \sum_{\epsilon} w(\pi, \epsilon) h(\epsilon / y) \geq s(\pi)$. If $-2\left(U^{\prime \prime} / U^{\prime}\right) \geq-U^{\prime \prime \prime} / U^{\prime \prime}$, on the other hand, the function $1 / U^{\prime}$ is convex. Applying Jensen's inequality to (8) once again, one gets an expression identical to (9) but with a reversed inequality. Therefore, $\forall \pi: \sum_{\epsilon}$ $w(\pi, \epsilon) h(\epsilon / y) \leq s(\pi)$.

The first part of the proposition is unsurprising: wages should rise with better signals on the regular or the environmental tasks. A more interesting statement is (ii), which says that the wage range under an environmental audit spans the wage range without one. Hence, an agent may be either better or worse paid after an environmental audit: the wage gradient becomes steeper and the agent is bearing more risk. Statement (iii) adds, furthermore, that the relative magnitude of $-2 U^{\prime \prime} / U^{\prime}$ and $-U^{\prime \prime \prime} / U^{\prime \prime}$ determines whether the expected wage after an audit occurs is larger or smaller than the wage when no audit has taken place. The ratio $-U^{\prime \prime} / U^{\prime}$ is the well-known coefficient of absolute risk aversion; it captures the agent's willingness to avoid risk. The ratio $-U^{\prime \prime \prime} / U^{\prime \prime}$, on the other hand, is the so-called 
index of absolute prudence; introduced by Kimball [22], it captures the strength of the agent's adjustment to risk or precautionary motives. The respective size of these two coefficients has recently been shown to play an important part in many situations involving risk and uncertainty (see Gollier and Treich [14]). Its intuitive role in the present context will become clearer in the next subsection, where we discuss the optimal occurrence of environmental audits.

\section{On the optimal occurrence of environmental audits}

The main difference between monitoring and auditing is that the latter's occurrence is contingent on specific events that can be chosen strategically by the principal. By selecting the revenue levels $\pi$ that trigger an environmental audit, the principal can influence the agent's allocation of effort in order to raise expected profit. The agent's reaction to the threat of audits will in turn depend on some characteristics of his utility function. It will now be shown that only two such characteristics - prudence and risk aversion - need to be considered in order to design an optimal auditing policy.

The first-order necessary conditions for $m(\cdot)$ - the probability of making an environmental audit - in problem (2) are given by

$$
\begin{array}{rlrl}
\forall \pi:\left(s-K-\sum h w\right)+\left(\sum U(w) h-U(s)\right)\left(\delta+\gamma \frac{f_{x}}{f}\right)+\lambda \sum U(w) h_{y} & \geq 0 & m=1 \\
& =0 & \text { if } & 0<m<1 \\
& \leq 0 & m=0
\end{array}
$$

Using equations (5) and (6), the left-hand expression simplifies into

$$
s-\frac{U(s)}{U^{\prime}(s)}+\sum\left[-w+\frac{U(w)}{U^{\prime}(w)}\right] h .
$$

Taking the derivative with respect to $\pi$, we get

$$
\frac{U U^{\prime \prime} s_{\pi}}{\left(U^{\prime}\right)^{2}}+\sum_{\epsilon}\left[-\frac{U U^{\prime \prime} w_{\pi}}{\left(U^{\prime}\right)^{2}}\right] h
$$

This reduces to 


$$
-\frac{U^{\prime \prime}(s) s_{\pi}}{\left(U^{\prime}(s)\right)^{2}}\left[-U(s)+\sum_{\epsilon} U(w) h(\epsilon \mid y)\right]
$$

by equation (7). By the assumptions and proposition 1 (i), the sign of the latter expression depends on the sign of the term within brackets. This yields the main result of this subsection.

PROPOSITION 2: Provided $K$ is not too high, $m(\pi)>0$ under the following circumstances:

(i) when $\pi$ is small, if $-2\left(U^{\prime \prime} / U^{\prime}\right) \geq-U^{\prime \prime \prime} / U^{\prime \prime}$;

(ii) when $\pi$ is large, if $-2\left(U^{\prime \prime} / U^{\prime}\right)<-U^{\prime \prime \prime} / U^{\prime \prime}$ and the agent's aversion to risk is small.

PROOF: Clearly, $\sum_{\epsilon} U(w(\pi, \epsilon)) h(\epsilon / y)-U(s(\pi)) \leq U\left(\sum_{\epsilon} w(\pi, \epsilon) h(\epsilon / y)\right)-U(s(\pi))$, by the concavity of $U$ and Jensen's inequality. Now, if $-2\left(U^{\prime \prime \prime} / U^{\prime}\right) \geq-U^{\prime \prime \prime} / U^{\prime \prime}$, proposition 1 (iii) implies that the latter expression is nonpositive. This entails that (13) is also nonpositive, and consequently the left-hand expression of (10) is nonincreasing in $\pi$. Hence, if $m(\pi)$ is positive, this will certainly happen at low values of $\pi$. This proves statement (i).

To prove (ii), note that the braketed term in (13) can be written as:

$$
\sum_{\epsilon} U(s(\pi)+k(\pi, \epsilon)) h(\epsilon \mid y)-U(s(\pi)) .
$$

By proposition 1 (iii), $\Sigma_{\epsilon} k(\pi, \epsilon) h(\epsilon / y)>0$. Thus (14) will be nonnegative, for all $\pi$, if the agent's risk aversion is sufficiently low. In this case, the left-hand expression in (10) will be nondecreasing. So if $m(\pi)$ turns up positive, it will do so at large values of $\pi$.

Q.E.D.

The conditions of the proposition can actually be made sharper. Assume, for instance, that the agent's utility function exhibits constant relative risk aversion. Without loss of generality, the agent's utility in this case is of the form $U(z)=(\alpha /(1-$ $\alpha))(z / \alpha)^{1-\alpha}$, where the coefficient of relative risk aversion, defined as $-z U^{\prime \prime}(z) / U^{\prime}(z)$, is precisely $\alpha$. Note that $-2 U^{\prime \prime} / U^{\prime}$ is less than, equal to, or greater than $-U^{\prime \prime \prime} / U^{\prime \prime}$ 
whenever $\alpha$ is less than, equal to, or greater than 1 . The comparison between $U(s)$ and $\sum_{\epsilon} U(w) h$ is now between

$$
\left(\frac{s}{\alpha}\right) \quad \text { and } \quad\left[\sum_{\epsilon}\left(\frac{w}{\alpha}\right)^{1-\alpha} h\right]^{\frac{1}{1-\alpha}} .
$$

By (8) we have that:

$$
\begin{aligned}
& \frac{1}{(s / \alpha)^{-\alpha}}=\sum_{\epsilon} h \frac{1}{(w / \alpha)^{-\alpha}}, \\
& \text { so }\left(\frac{s}{\alpha}\right)=\left[\sum_{\epsilon} h\left(\frac{w}{\alpha}\right)^{\alpha}\right]^{\frac{1}{\alpha}} .
\end{aligned}
$$

Thus, $s / \alpha$ is larger than the right-hand term of (15), and so $m(\pi)>0$ at low values of $\pi$, if

$\alpha<1 / 2$. When $\alpha>1 / 2$, on the other hand, $s / \alpha$ becomes smaller than the right-hand expression in (15), so $m(\pi)$ is positive at high values of $\pi{ }^{11}$

Let us now turn to the intuition behind propositions 1 and 2. Let us denote the coefficient of absolute risk aversion and the index of absolute prudence by $A=$ $-U^{\prime \prime} / U^{\prime}$ and $P=-U^{\prime \prime \prime} / U^{\prime \prime}$ respectively. When $2 A \geq P$, the agent's risk aversion is high enough so that he would try hard to avoid the worst outcome of an environmental audit, which is getting paid a low wage $w(\pi, \epsilon)<s(\pi)$ after a small estimate $\epsilon$ of environmental cost reduction is observed. This implies that the agent might spend too much effort on environmental protection, at the expense of regular business activities. One obvious way for the principal to restore a balance is to worsen the outcome associated with poor revenue performance: she will then run an environmental audit when $\pi$ is low and decrease the agent's expected wage in this case. If $2 A \leq P$, on the other hand, the agent's precautionary motives clearly dominates his risk aversion. This means that the agent will seek not so much to

11 Baiman and Demski [1] assume that the agent's utility function belongs to the HARA family, which includes utility functions with constant, increasing or decreasing absolute or relative risk aversion, and state propositions 1 and 2 referring to the parameters of the agent's utility function instead of comparing the index of prudence with the coefficient of absolute risk aversion. The latter approach, however, in addition to bringing slightly more general results, contributes a clearer understanding of the agent's effort allocation incentives. 
avoid the bad outcomes associated with an environmental audit, but rather to increase his expected income when facing such an audit. This expected income is

given by $\sum_{\epsilon} w(\pi, \epsilon) h$ and it is increasing in $\pi$, so this time the agent might care too much about regular business duties at the expense of the environment. One way for the principal to fix this is to conduct environmental audits when $\pi$ is high, and to mitigate the agent's prudence by increasing his expected wage when an audit takes place.

The latter situation seems to agree better with common sense and casual observation. For it seems more plausible that business firms would deem environmental negligence to be likely, and would therefore conduct an environmental audit, when they get unusually high short-term revenues. This belief is actually not inconsistent with the widely accepted assumption that absolute risk aversion is decreasing. To see this, first note that

$$
\frac{A^{\prime}(z)}{A(z)}=\frac{d}{d z} \ln \left(\frac{-U^{\prime \prime}(z)}{U^{\prime}(z)}\right)=\frac{U^{\prime \prime \prime}(z)}{U^{\prime \prime}(z)}-\frac{U^{\prime \prime}(z)}{U^{\prime}(z)}=A(z)-P(z)
$$

If absolute risk aversion decreases at a sufficiently high rate, we have that $2 A \leq P$, and the intuitive scenario unfolds by the above propositions.

\section{Environmental audits and effort allocation}

A contract that includes the possibility of environmental audits raises the principal's cost in two ways compared with a contract without any audits. First, it entails the direct cost of the audits; second, it may raise the expected wage cost. Offsetting this, however, is the increase in revenue that might come from the reallocation of the agent's effort which the threat of audits induces. The next proposition makes precise the set of circumstances where such an increase actually happens.

PROPOSITION 3: The introduction of environmental audits brings an increase in the agent's effort $y$ directed at the environment. Moreover, if $2 \mathrm{~A} \geq \mathrm{P}$, or if $2 \mathrm{~A}<\mathrm{P}$ and the agent is not too risk averse, a positive probability of an environmental audit also induces an increase in the effort $x$ spent on regular tasks.

PROOF: Consider the incentive compatibility constraint of problem (1), and denote as $E U$ the objective - the expected utility - which the agent seeks to maximize. Let us compute the following cross partial derivatives: 


$$
\begin{gathered}
\forall \pi: \quad \frac{\partial E U}{\partial x \partial m(\pi)}=\sum_{\epsilon}[U(w(\pi, \epsilon)) h(\epsilon \mid y)-U(s(\pi))] f_{x}(\pi \mid x) . \\
\forall \pi: \quad \frac{\partial E U}{\partial y \partial m(\pi)}=\sum_{\epsilon} U(w(\pi, \epsilon)) h_{y}(\epsilon \mid y) f(\pi \mid x) .
\end{gathered}
$$

Notice that the right-hand side of the latter equation is always positive because of the monotone likelihood property of $h$. By theorem 5 in [25], it follows that the agent's optimal environmental effort $y$ will increase whenever $m(\pi)$ increases. Notice also that, by the results of the previous subsections, the right-hand side of (18) is nonnegative under the circumstances described in proposition 3. Again, we conclude that the agent's optimal effort on regular tasks would not decrease after an increase of $m(\pi)$ in the relevant range. This proves the proposition.

Q.E.D.

According to this proposition, the amounts of effort devoted by the agent to regular activities and to environmental protection can become complementary arguments of the agent's payoff function under an optimal audit policy. This is a striking result, given that the agent was assumed to be indifferent $a$ priori between working on regular business activities versus environmental protection ( $x$ and $y$ are substitutes in the agent's cost function). It has an intuitive rationale, however. Since $s(\pi)>w(\pi, \epsilon)$ when $\epsilon$ is small but $s(\pi)<w(\pi, \epsilon)$ when it is large (proposition 1 ), the agent will always increase the effort $y$ spent on the environment, in order to make it more likely that the outcome of an environmental audit will be a favorable one. But the agent can also make the occurrence of an audit more or less probable by adjusting the effort $x$ spent on standard business duties. If $2 \mathrm{~A}>\mathrm{P}$, then audits occur when $\pi$ is low, and they are conceived as a punishment since they bring the agent's expected wage down; in this case the agent also has an incentive to make environmental audits less frequent, and he can do so by increasing $x$ as well. If $2 \mathrm{~A}$ $<\mathrm{P}$ and the agent is not too risk averse, on the other hand, environmental audits are triggered by high short-term profits $\pi$, and they constitute a reward for the agent since they yield a higher expected wage; in this case the agent would like to be audited and would therefore make audits more frequent by increasing his effort $x$.

This result has interesting implications for environmental policy. There is an active debate nowadays as to whether stricter environmental regulation by one 
nation would render its firms more competitive or would rather increase their cost and therefore harm their relative market position [27, 28]. The latter proposition suggests that a policy of promoting environmental auditing could actually be consistent with the former scenario, as properly designed environmental audits would also increase employees' effort on standard business duties.

\section{CONCLUSION}

The International Chamber of Commerce believes that effective protection of the environment is best achieved by an appropriate combination of legislation/regulation and of policies and programs established voluntarily by industry. (...) Environmental auditing is an important component of such voluntary policies. [18, p. xvii-1]

The practice of environmental auditing is currently being standardized and is spreading to many industries which, unlike the chemical industry, did not previously use such a tool for managing environmental resources. This paper studied a particular kind of environmental audits, where the information obtained through an audit influences the agent's compensation. On the positive side, proposition 3 explains why many firms might be willing to implement these environmental audits. On the normative side, the first two propositions prescribe that, in a context where employees have some discretion on how they will distribute their effort between standard business functions and environmental protection, the occurrence of environmental audits and the optimal wage structure should depend on the importance of employees' precautionary motives relative to their risk aversion.

We shall now make a few comments concerning environmental public policy. As we remarked at the beginning of the paper, new environmental auditing standards are now being actively promoted by public authorities to be voluntarily adopted by firms. At first sight, the involvement of public policy makers may look surprising. First, it is well known amongst environmental economists that there are other more traditional instruments the regulator could use instead, such as command and control regulations, effluent fees and marketable permits. These policies, however, are conceived as constraints on profit maximization and are unconcerned with the process by which managers solve problems. Increasingly, public policy makers seem rather to favor instruments that "pierce the corporate veil" and take into account management processes. Such instruments include environmental auditing, but also court-imposed organizational remedies, product eco-labelling 
policies, and individual (as opposed to corporate) criminal liability. In our view, this comes in recognition of the fact that most environmental resources are allocated by managers within business firms ${ }^{12}$ so organizational failures could be as important a cause of environmental depletion as market failures (i.e. externalities).

But now, why should voluntary environmental audits be a public policy instrument? After all, the first ones were mandated by the regulator and subsequent ones were set up by narrow then broad industry associations. ${ }^{13}$ Clearly, as for the adoption of technological standards, public support to particular rules of environmental auditing aims at accelerating the international harmonization (and therefore comparison) of environmental practices, since failure to achieve this may ultimately be detrimental to trade and competition. Another set of considerations is the impact on contracting habits and the costs of running environmental audits that the presence of established and widespread rules for environmental auditing may have. On the one hand, harmonization may significantly lower auditing costs. ${ }^{14}$ One can expect that over time, environmental auditing will parallel financial auditing and be highly routinized, efficient, and reliable to both internal and external users. On the other hand, harmonization will also make the results of environmental audits verifiable by third parties and in particular the courts, so it should make contingent contracts based on those results - which is precisely the type of contracts we emphasized - feasible.

\footnotetext{
${ }^{12}$ According to some recent studies by the United Nations reported in [19], the world's 500 largest companies are responsible for $70 \%$ of world trade, $60 \%$ of foreign investment and $30 \%$ of world gross domestic product.

${ }^{13}$ A few countries - Brazil for example - are maintaining mandatory environmental audits [see 23] But this is the exception rather than the rule.

${ }^{14}$ As one indication of the benefits harmonization may bring, according to [29] Ciba Clayton took three man-years to establish the eco-management system at its first registered site in the United Kingdom, including time talking with other companies regarding the requirements of the then-nascent standards The company estimates that the time would be cut by two-thirds under the final version of EMAS.
} 


\section{REFERENCES}

1. S. Baiman and J. S. Demski, Economically optimal performance evaluation and control systems, J. Accounting Research 18, 184-220 (1980).

2. R. D. Banker, S. M. Datar, and A. Maindiratta, "Unobservable outcomes and multi-attribute preferences in the evaluation of managerial performance," Working paper 86-11, Carnegie-Mellon University (1986).

3. D. Bergemann, "Multiple tasks in the principal-agent model," CARESS Working Paper \#92-33, University of Pennsylvania (1992).

4. British Standards Institute, "Specification for Environmental Management Systems, BS7750", British Standard Institute, London, UK (1992).

5. Business International, "Managing the Environment. The Greening of European Business," Business International Ltd, London, UK (1990).

6. L. B. Cahill and R. W. Kane, "Environmental Audits," Government Institutes Inc., Rockville, MA (1989).

7. Commission of the European Communities, "EC Council: Regulation Setting Up an EC Eco-Management and Audit Scheme," European Union, Brussels (1993).

8. , "Toward Sustainability: A European Community Programme of Policy and Action in Relation to the Environmental and Sustainable Development," Vol. II, European Union, Brussels (1992).

9. , A Consultation Paper on Draft Elements for a Council Directive on the Environmental Auditing of Certain Industrial Activities", document No. XI/632/90, European Union, Brussels (1990).

10. R. A. Dye, Optimal monitoring in agencies, Rand J. Econom. 17, 339350 (1986).

11. The Economist, "A survey of industry and the environment," Vol. 23 (1990).

12. M. Flaherty and A Rappoport, "Multinational corporations and the environment: A survey of global practices," The Center for Environmental Management, Tufts University (1991). 
13. H. L. Gabel and B. Sinclair-Desgagné, Managerial incentives and environmental compliance, J. Environ. Econom. Management, 24, 229$240(1993)$.

14. C. Gollier and N. Treich, "Optimal dynamic exposure to uncertainty with scientific progress: An economic interpretation of the Precautionary Principle," mimeo, University of Toulouse.

15. L. L. Harrison, "The McGraw-Hill Environmental Auditing Handbook: A Guide to Corporate and Environmental Risk Management," McGraw-Hill, New York (1984).

16. B. Holmström, Moral hazard and observability, Bell J. Econom. 10, 74-91 (1979).

17. B. Holmström and P. Milgrom, Multitask principal-agent analyses: incentive contracts, asset ownership, and job design, J. Law, Econom. and Org. 7, 24-52.

18. International Chamber of Commerce, "Environmental Auditing," ICC Publishing, Paris (1989).

19. International Herald Tribune, Business sets guidelines for sustainable growth, 1 June 1992.

20. P. James and M. Bennett, Environment-related performance in business, UNEP Industry and Environment 18, 40-43 (1995).

21. S. K. Kim, Efficiency of an information system in an agency model, Econometrica 63, 52-89 (1995).

22. M. S. Kimball, Precautionary savings in the small and in the large, Econometrica 58, 53-73 (1990).

23. E. Lèbre La Rovere and A. d'Avignon, Emerging environmental regulations in Brazil and the prospects for their implementation, UNEP Industry and Environment 18, 11-13 (1995).

24. Mckinsey and Company, "Corporate Responses to the Environmental Challenge - Summary Report," Mckinsey, Amsterdam (1991).

25. P. Milgrom and C. Shannon, Monotone comparative statics, Econometrica 62, 157-180 (1994). 
26. D. Mookherjee and I. Png, Optimal auditing, insurance and redistribution, Quarterly. J. Econom. 104, 399-415 (1989).

27. K. Palmer, W. E. Oates and P. Portney, Tightening environmental standards: The benefit-cost or the no-cost paradigm, J. Econom. Perspectives 9, 119-131 (1995).

28. M. E. Porter and C. van der Linde, Towards a new conception of the environment-competitiveness relationship, J. Econom. Perspectives 9, 97118 (1995).

29. B. Rothery, "Implementing the Environment Management Standard and the EC Eco-Management Scheme," Gower Press, Aldershot (1993).

30. B. Sinclair-Desgagné, The first-order approach to multi-signal principalagent problems, Econometrica 62, 459-465 (1994).

31. L. S. Spedding, D. M. Jones, and C. J. Dering, "Eco-Management and Eco-Auditing: Environmental Issues for Business," Chancery Law Publishing, London (1993).

32. J. Stans, Development of ISO standards for environmental auditing, UNEP Industry and Environment 18, 24-27 (1995).

33. R. M. Townsend, Optimal contracts and competitive markets with costly state verification, J. Econom. Theory 21, 265-293 (1979).

34. UNEP, Environmental management tools: facts and figures, UNEP Industry and Environment 18 , 3-10 (1995). 


\section{Liste des publications au CIRANO *}

\section{Cahiers CIRANO / CIRANO Papers (ISSN 1198-8169)}

\begin{tabular}{|c|c|}
\hline $96 c-1$ & $\begin{array}{l}\text { Peut-on créer des emplois en réglementant le temps de travail ? / par Robert } \\
\text { Lacroix }\end{array}$ \\
\hline $95 c-2$ & $\begin{array}{l}\text { Anomalies de marché et sélection des titres au Canada / par Richard Guay, Jean- } \\
\text { François L'Her et Jean-Marc Suret }\end{array}$ \\
\hline $95 \mathrm{c}-1$ & La réglementation incitative / par Marcel Boyer \\
\hline $94 c-3$ & $\begin{array}{l}\text { L'importance relative des gouvernements : causes, conséquences et organisations } \\
\text { alternative / par Claude Montmarquette }\end{array}$ \\
\hline $94 c-2$ & $\begin{array}{l}\text { Commercial Bankruptcy and Financial Reorganization in Canada / par Jocelyn } \\
\text { Martel }\end{array}$ \\
\hline $94 c-1$ & $\begin{array}{l}\text { Faire ou faire faire : La perspective de l'économie des organisations / par Michel } \\
\text { Patry }\end{array}$ \\
\hline
\end{tabular}

Série Scientifique / Scientific Series (ISSN 1198-8177)

\begin{tabular}{|c|c|}
\hline $96 s-20$ & $\begin{array}{l}\text { Arbitrage-Based Pricing When Volatility Is Stochastic / Peter Bossaert, Eric } \\
\text { Ghysels, Christian Gouriéroux }\end{array}$ \\
\hline $96 \mathrm{~s}-19$ & $\begin{array}{l}\text { Kernel Autocorrelogram for Time Deformed Processes / Eric Ghysels, Christian } \\
\text { Gouriéroux, Joanna Jasiak }\end{array}$ \\
\hline $96 \mathrm{~s}-18$ & A Semi-Parametric Factor Model for Interest Rates / Eric Ghysels, Serena Ng \\
\hline $96 s-17$ & $\begin{array}{l}\text { Recent Advances in Numerical Methods for Pricing Derivative Securities } \\
\text { Mark Broadie, Jérôme Detemple }\end{array}$ \\
\hline $96 \mathrm{~s}-16$ & $\begin{array}{l}\text { American Options on Dividend-Paying Assets / Mark Broadie, Jérôme } \\
\text { Detemple }\end{array}$ \\
\hline $96 \mathrm{~s}-15$ & Markov-Perfect Nash Equilibria in a Class of Resource Games / Gerhard Sorger \\
\hline $96 s-14$ & Ex Ante Incentives and Ex Post Flexibility / Marcel Boyer et Jacques Robert \\
\hline $96 s-13$ & $\begin{array}{l}\text { Monitoring New Technological Developments in the Electricity Industry: An } \\
\text { International Perspective / Louis A. Lefebvre, Élisabeth Lefebvre et } \\
\text { Lise Préfontaine }\end{array}$ \\
\hline $96 s-12$ & $\begin{array}{l}\text { Model Error in Contingent Claim Models Dynamic Evaluation / Eric Jacquier } \\
\text { et Robert Jarrow }\end{array}$ \\
\hline $96 s-11$ & $\begin{array}{l}\text { Mesures de la croissance de la productivité dans un cadre d'équilibre général: } \\
\text { L'Économie du Québec entre } 1978 \text { et } 1984 \text { / Pierre Mohnen, Thijs } \\
\text { ten Raa et Gilles Bourque }\end{array}$ \\
\hline $96 s-10$ & $\begin{array}{l}\text { The Efficiency of Collective Bargaining in Public Schools / Daniel S. Hosken } \\
\text { et David N. Margolis }\end{array}$ \\
\hline $96 \mathrm{~s}-09$ & $\begin{array}{c}\text { Constant Consumption and the Economic Depreciation of Natural Capital : The } \\
\text { Non-Autonomous Case/John M. Hartwick et Ngo Van Long }\end{array}$ \\
\hline $96 \mathrm{~s}-08$ & $\begin{array}{l}\text { Upstream-Downstream Specialization by Integrated Firms in a Partially } \\
\text { Integrated Industry / Gérard Gaudet, Ngo Van Long et Antoine } \\
\text { Soubeyran }\end{array}$ \\
\hline
\end{tabular}

-Vous pouvez consulter la liste complète des publications du CIRANO et les publications elles-mêmes sur notre site World Wide Web à l'adresse suivante :

http://www.cirano.umontreal.ca/publication/page1.html 